\title{
FORMAÇÃO DE PROFESSORES: DESAFIOS E POSSIBILIDADES SOBRE OS SABERES TEÓRICOS E PRÁTICOS NO PROCESSO FORMATIVO DO ACADÊMICO DE PEDAGOGIA
}

\author{
TEACHER TRAINING: CHALLENGES AND POSSIBILITIES \\ ABOUT THEORETICAL AND PRACTICAL KNOWLEDGE IN \\ THE FORMATIVE PROCESS OF THE \\ PEDAGOGY ACADEMIC
}

Mânia Maristane Neves Silveira Maia ${ }^{1}$ Luzia Leidjane Mendonça Fernandes ${ }^{2}$

\begin{abstract}
RESUMO
Este artigo apresenta os resultados de uma pesquisa monográfica que foi realizada com professoras regentes do $1^{\circ}$ ao $5^{\circ}$ ano de três escolas da cidade de Paracatu MG, e teve como principal objetivo em analisar os desafios e as possibilidades sobre os saberes teóricos e práticos no processo formativo do acadêmico de Pedagogia para o exercício da docência. Utilizou-se uma pesquisa de abordagem qualitativa, descritiva, bibliográfica e de campo, o instrumento de coleta de dados foi um questionário estruturado, aplicado no mês de Julho de 2019. A amostra contou com seis professoras efetivas da Rede Municipal de Paracatu. Para atingir o objetivo proposto foi feito uma pesquisa bibliográfica baseada em autores, como: Imbernón (2001 e 2010); Libâneo (2005 e 2007) e Nóvoa (1991, 1992, 1997 e 2003). Após a realização da pesquisa, a análise e interpretação dos dados coletados foram feita a luz do referencial teórico. Por meio dessa pesquisa, foi possível compreender que os saberes teóricos abordados no curso de formação de professores, bem como os saberes práticos contribuem para uma prática pedagógica satisfatória.
\end{abstract}

Palavras-chave: Formação de Professores. Saberes teóricos e práticos. Pedagogia.

\section{ABSTRACT}

This article presents the results of a monographic research that was carried out with leading teachers from the 1st to the 5th year of three schools in the city of Paracatu - MG, and had as main objective to analyze the challenges and the possibilities about the theoretical and practical knowledge in the process training of the academic of Pedagogy for the exercise of teaching. A qualitative, descriptive, bibliographic and field research was used, the data collection instrument was a structured questionnaire, applied in July 2019. The sample included six effective teachers from the Municipal Network of Paracatu. To achieve the proposed objective, a bibliographic search based on authors was carried out, such as: Imbernón (2001 and 2010); Libâneo (2005 and 2007) and Nóvoa (1991, 1992, 1997 and 2003). After conducting the research, the analysis and interpretation of the collected data were made in the light of the theoretical framework. Through this research, it was possible to understand that the theoretical knowledge covered in the teacher training course, as well as the practical knowledge contribute to a satisfactory pedagogical practice.

Keywords: Teacher Education. Theoretical and practical knowledge. Pedagogy.

\footnotetext{
Doutoranda pela Universidade Federal de Santa Catarina, Mestre em Educação pela Universidade Federal dos Vales do Jequitinhonha e Mucuri - UFVJM e Professora titular do Departamento de Estágios e Práticas Escolares na UNIMONTES. E-mail: maniamaia@yahoo.com.br. Lattes: http://lattes.cnpq.br/2724512117715250

2 Graduada em Pedagogia pela Universidade Estadual de Montes Claros - UNIMONTES. 


\section{Introdução}

Este trabalho tem como finalidade discorrer sobre a relevância dos desafios e as possibilidades em relação aos saberes teóricos e práticos no processo formativo do acadêmico de pedagogia. Sendo uma pesquisa Bibliografia, de campo e de caráter qualitativo. Essa pesquisa amostral foi realizada através de um questionário que contou com seis respondentes.

Compreende-se a importância do processo formativo para a construção dos conhecimentos teóricos e práticos do acadêmico do Curso de Pedagogia, a fim de contribuir para o exercício da docência.

O professor é um profissional que media o conhecimento, nessa perspectiva, entende-se que a formação do professor é indispensável para a prática educativa, a qual se constitui o lócus de sua profissionalização cotidiana no cenário escolar. Dessa forma, é preciso compreender que formação docente incide na reflexão fundamental de que ser professor é ser um profissional da educação que trabalha com pessoas, e consequentemente enfrenta desafios, mas também possui possibilidades. Nesse sentido, o docente necessita de um processo permanente de formação, em busca do conhecimento constante que dão suporte à teoria aprendida e tão logo, a sua prática pedagógica e social.

\section{Formação de Professores: Reflexões iniciais}

Negrine (1997) destaca que a formação de professores caracteriza-se como sendo a que, do ponto de vista acadêmico, credencia o indivíduo a atuar em determinada área do conhecimento e é adquirida com a conclusão do curso de licenciatura ou bacharelado. Nesse sentido pode cumprir:

[...] um papel importante na configuração de uma "nova" profissionalidade, docente, estimulando a emergência de uma cultura profissional no seio do professorado e de uma cultura organizacional no seio das escolas (NÓVOA, 1992, p.24).

A formação do professor passa a ser como um desenvolvimento de ações que propiciem uma constante retomada dos conhecimentos específicos com os quais trabalha, possibilitando reflexões em torno da sua prática para que seja possível corrigir quaisquer que sejam os constrangimentos, permitindo por sua vez uma atualização constante dos conhecimentos cognitivos do mesmo.

Há três etapas relacionadas aos modelos de formação: a formação inicial, a iniciação ao ensino e a formação contínua. A primeira etapa de formação do professor corresponde ao 
período em que este passa numa instituição de formação a adquirir conhecimentos e a desenvolver competências profissionais. A segunda, é identificada como a fase de indução e corresponde aos primeiros anos em que o professor exerce a sua profissão na sala de aula onde desenvolve as suas competências e conhecimentos através da prática. E a última etapa de formação é a formação contínua, inclui, "ações ou estratégias de desenvolvimento, planificadas ou não, individualmente ou em grupo.” (MARCELO, 1999, p. 52).

Diante desse reconhecimento a formação deste profissional passou a ser oferecida nos Cursos de Pedagogia como sendo formação inicial, até a oferta de formação continuada ser garantida pelas redes de ensino. Destaca-se a necessidade intrínseca para os profissionais da educação escolar, e faz parte de um processo permanente de desenvolvimento profissional que deve ser assegurado a todos. A formação deve propiciar atualizações, sobre a prática educativa, promovendo um processo constante de auto avaliação que oriente a construção contínua de competências profissionais (BRASIL, 2002).

Entende-se que a formação necessária não é apenas para aprimorar a ação do professor ou melhorar a sua prática pedagógica. A formação é um direito de todos os professores, é conquista e direito da população, por uma escola pública bem mais preparada composta por profissionais capacitado.

É importante entender que a formação deve ser diária, que a mesma não é estática e por isso os professores devem estar sempre procurando conhecimentos em suas formações para não se limitarem, sendo, portanto professores reflexivos. Nesse sentido, a formação continuada proporciona:

[...] novas reflexões sobre a ação profissional e novos meios para desenvolver o trabalho considera-se a formação continuada como um processo de construção permanente do conhecimento e desenvolvimento profissional, a partir da formação inicial e vista como uma proposta mais ampla, de hominização, na qual o Homem Integral, produzindo-se a si mesmo, também se produz em interação com o coletivo." (NUNES, 2000, p. 9).

Neste sentido, considerando os professores básicos ou profissionais estratégicos para o desenvolvimento da sociedade, estes precisam deter formação. Demo (1999) argumenta que o diploma do professor deveria ser provisório para que o mesmo o renovasse continuamente. Dizendo que na prática os professores fazem alguma coisa de vez em quando, como participar em semanas pedagógicas, escutar alguma conferência, reunir-se para discutir, etc. 


\section{Saberes teóricos e práticas da docência}

Segundo Pimentel (2014) é necessário para práticas da docência, que os conhecimentos teóricos tenham sentido e significado para que se possa perceber a relação entre a teoria e as ações cotidianas. Desta forma, também deve-se incluir nos currículos dos cursos de formação de professores o estudo de situações reais.

Contudo, a formação de professores tem a tendência de adotar como referências as dimensões coletivas das práticas, contribuindo para a: “emancipação profissional e para a consolidação de uma profissão que é autônoma na produção de seus saberes e de seus valores." (NÓVOA, 1991, p.25).

O trabalho teórico, que por sua vez não prescinde da prática, é aquele que:

[...] determinará a diferença entre prática enquanto repetição reiterada de ações que deixam tudo como está e práxis enquanto processo resultante do contínuo movimento entre teoria e prática, entre pensamento e ação, entre velho e novo, entre sujeito e objeto, entre razão e emoção, entre homem e humanidade, que produz conhecimento, e por isto revoluciona o que está dado, transformando a realidade (KUENZER, 2003, p.24).

Assim, é possível entender o docente como sujeito de uma prática pedagógica, considerando o seu papel na formação de outros sujeitos. Nesse sentido a formação de professores assume um processo pelo qual, o professor aprende e desenvolve habilidades inerentes à sua prática, embasado em teorias aprendidas em sua capacitação.

A prática não é uma cópia da teoria e nem esta é um reflexo daquela. A prática é o próprio modo como às coisas vão sendo feitas cujo conteúdo é atravessado por uma teoria. Assim a realidade é um movimento constituído pela prática e pela teoria como momentos de um dever mais amplo, consistindo a prática no momento pelo qual se busca fazer algo, produzir alguma coisa e que a teoria procura conceituar, significar e com isto administrar o campo e o sentido desta atuação (BRASIL, CNE, 28/2001, p. 9).

A formação de professores deve contribuir para que estes em formação se formem primeiramente como pessoas, conseguindo compreender a sua responsabilidade no desenvolvimento da escola de forma a adquirir uma atitude reflexiva acerca do seu ensino e da sua prática educativa. Uma vez que o professor assume um papel social importante e necessita desempenhar uma atividade profissional teórica e prática.

Dessa forma, coloca-se em evidência o professor reflexivo, que para Schön (1997), aprende a atividade, constrói, de forma pessoal, seu conhecimento profissional o qual, incorpora e ultrapassa o conhecimento emergente institucionalizado. 
Ao refletir sobre sua ação pedagógica, ele estará atuando como um pesquisador da sua própria sala de aula, deixando de seguir cegamente as prescrições impostas pela administração escolar (coordenação pedagógica e direção) ou pelos esquemas preestabelecidos nos livros didáticos, não dependendo de regras, técnicas, guia de estratégias e receitas decorrentes de uma teoria proposta/imposto fora, tornando-se ele próprio um produtor de conhecimento profissional e pedagógico (BOLZAN, 2002, p.17).

Diante desta afirmação, entende-se que o educador além de reflexivo, deve ser crítico mediante as suas ações pedagógicas. Sendo assim, compreende-se que esse processo de reflexão crítica, é realizado individualmente ou em grupo. Quanto aos cursos de formação e a identidade do educador, diz que:

A identidade do educador, pressuposto fundamental da reconstrução dos cursos de formação, constrói-se no jogo das relações sociais no contexto da sociedade ampla diversificada, em que se correlacionam a divisão social do trabalho e comprometimentos. Torna-se imprescindível ao coletivo da profissão saber como o inteiro sistema das determinações sociais o atravessa e, reciprocamente, como ele, coletivo, atua sobre os dinamismos sociais. Compete-lhe política de inserção ativa no todo das relações sociais e no todo das relações específicas dos saberes a partir de que e com que trabalha (MARQUES, 2000, p.61).

Nesse sentido, cabe refletir sobre a perspectiva profissional, entendendo que:

O conhecimento pedagógico e o saber prático colocam em ação um processo em especial, em que conceitos e ideias são reconstruídos em uma nova síntese que tem o poder de transformar, qualitativamente, a prática. Por conseguinte, a apropriação de uma teoria também produz um novo nível de compreensão que corresponde a uma transformação da prática. Esse processo se caracteriza como

um ciclo que não tem início, nem final, uma vez que o novo influi sobre o antigo, sendo incorporado aos múltiplos elementos que constituem o novo saber fazer (BOLZAN, 2002, p.155).

Com base nesses argumentos, é possível perceber que a formação do professor é a responsável por dar a este profissional um suporte para o exercício da sua prática dentro do contexto escolar. É importante considerá-lo detentor de uma profissão na qual o próprio sujeito histórico é capaz de produzir o seu próprio ofício, explicitando as teorias e as práticas pedagógicas a serem desempenhadas.

\section{Desafios no processo formativo}

É importante que no processo formativo dos acadêmicos do Curso de Pedagogia, estes sejam reconhecidos como sujeitos do conhecimento, capazes de realizar um trabalho que abrace as expectativas cognitivas, afetivas e sociais; a subjetividade.

Tardif (2008, p.241) aponta que: “o principal desafio para a formação de professores, nos 
próximos anos será o de abrir um espaço maior para os conhecimentos práticos dentro do próprio currículo". Assim, nesse processo os acadêmicos passam alguns anos assistindo aulas baseadas em disciplinas, para então aplicarem esses conhecimentos. Na lógica disciplinar o conhecimento se sobrepõe a ação, mas, numa prática, aprender é fazer e conhecer fazendo.

No processo formativo docente, não se pode ser ensinado apenas o básico para a reprodução do conhecimento dominante. Em seu pensamento, Imbernón (2011), pontua que a falta de conexão entre os saberes aprendidos no processo formativo torna essa dimensão deficiente.

Diante do ponto de vista de Tardif (2008), muitas concepções teóricas abordadas na formação de professores podem ter sido concebidas sem relação ao ensino dentro da realidade em que o docente atua. Isto pode fazer com que estes conhecimentos não sejam úteis no momento da atuação efetiva na sala de aula.

Nessa perspectiva, o desafio atual, segundo Nóvoa (1992) consiste na valorização de paradigmas de formação que promovam a preparação de professores reflexivos, que assumam a responsabilidade do seu próprio desenvolvimento profissional e que participem como protagonistas na implementação das políticas educativas.

Assim, em relação à postura do professor investigador, que realize pesquisas científicas. André (2001) ao afirmar que a pesquisa científica, exige a coleta e a análise sistemática de dados, ressalta a sua importância dentro dos cursos de formação de professores. Considera-se que para isso, alguns princípios da pesquisa sejam incorporados no cotidiano pedagógico, de forma a levar o professor a questionar, compreender, e repensar sua postura pedagógica, propiciando melhores situações de aprendizagem.

\footnotetext{
O papel da pesquisa na formação docente vai muito além da questão do professor pesquisador/reflexivo, que ora é vista como panacéia, ora como impossibilidade. Requer, por um lado, que se considere a existência de várias modalidades de articulação entre ensino e pesquisa na formação docente e, por outro lado, que se reconheça a necessidade de condições mínimas para que o professor possa aliar a investigação a seu trabalho docente cotidiano (ANDRÉ, 2001, p. 62).
}

Embora seja essencial uma formação para a pesquisa, compreende-se que esse tem sido um desafio no processo formativo de professores, uma vez que, segundo Lüdke (2001) os cursos de formação inicial de professores ainda investem pouco em pesquisa. Contudo, salienta-se que o principal objetivo do ensino da pesquisa nos cursos de formação docente é o processo de ensino e aprendizagem dos conteúdos escolares da educação básica. 
[...] nos encontramos em uma encruzilhada fértil: de um lado, o reconhecimento da importância da pesquisa para o professor, de outro, o desafio de lhe assegurarmos as condições e a abertura para todas as formas de pesquisar que sejam necessárias para a busca de soluções aos seus problemas, sem comprometer o próprio estatuto de pesquisa (LÜDKE, 2001, p. 52).

Ao garantir que os acadêmicos em formação possam refletir sobre a natureza da ciência, dá-se um passo para transformação da realidade na qual se encontra inserido. Galiazzi (2003, p. 56) aponta que: “a pesquisa em educação colabora para a compreensão de aspectos epistemológicos relacionados ao conhecimento profissional do professor”.

Diante disso, acredita-se que a prática de formar pela pesquisa seja uma maneira de abordar e problematizar a visão do ser professor, de tornar os acadêmicos em formação, mais críticos e participativos. Assim, é possível destacar que o processo formativo é como o lócus privilegiado da formação contínua, Candau (1996) ressalta que esse processo precisa apoiar-se numa prática reflexiva, capaz de identificar os problemas e buscar soluções.

\section{Contribuições do processo formativo para o exercício da docência}

Para Nóvoa (1999), conhecer o professor, a sua formação e como ele se constrói ao longo da sua carreira profissional, é indispensável para compreender as práticas pedagógicas dentro das instituições de ensino. Dessa forma, entende-se que para o exercício da docência um processo formativo de qualidade, uma vez que a docência exige aperfeiçoamento de práticas constantes, bem como conhecimentos e saberes contínuo. O trabalho docente envolve o processo formativo, os conhecimentos que adquiriram em sua formação.

Segundo Mizukami (2004), a base de conhecimentos para o ensino é entendida como um corpo de compreensões, conhecimentos, habilidades e disposições que são necessários para que o professor possa propiciar processos de ensinar e de aprender, em diferentes áreas de conhecimento, níveis, contextos e modalidades de ensino.

A competência básica de todo e qualquer professor é o domínio do conteúdo específico. Somente a partir deste ponto é possível construir a competência pedagógica. Esta afirmação não implica a existência de uma relação temporal de sucessão, e sim de uma articulação epistemológica (CANDAU, 1997, p. 46).

Sendo assim, o conhecimento do conteúdo específico, envolve segundo Imbernón (2001), as metodologias e estratégias de ensino se relacionando à experiência docente, como a capacidade de adaptabilidade, já vivenciada nas disciplinas de Estágio Curricular Supervisionado. Analisando o processo formativo estando diretamente associado ao exercício da docência compreendem-se as contribuições deste para a transformação de suas práticas 
pedagógicas e nas possíveis mudanças do contexto escolar.

\begin{abstract}
O conhecimento profissional consolidado mediante a formação permanente apoia-se tanto na aquisição de conhecimentos teóricos e de competências de processamento da informação, análise e reflexão crítica em, sobre e durante a ação, o diagnóstico, a decisão racional, a avaliação de processos e a reformulação de projetos (IMBERNÓN, 2010, p.75).
\end{abstract}

Formar-se professor é refletir sobre o ensino, o processo formativo para o exercício da docência, é uma questão de suma importância, segundo Nóvoa (2003 p.23): “O aprender contínuo é essencial e se concentra em dois pilares: a própria pessoa, como agente, e a escola como lugar de crescimento profissional permanente". Nesse sentido, a formação teórica e a prática poderão contribuir para o melhoramento da qualidade de ensino, onde se necessita de uma qualificação profissional e pessoal.

\title{
Procedimentos Metodológicos
}

Utilizou-se uma pesquisa de abordagem qualitativa. Conforme Goldenberg (1997), não permite que o pesquisador faça julgamentos, preconceitos que possam contaminar. Trata-se de uma pesquisa bibliográfica que segundo Lehfeld (1991), refere-se à pesquisa cujo objetivo é descobrir e interpretar os fatos que estão inseridos em uma determinada realidade.

Também é uma pesquisa de campo, pois existe a coleta de dados junto as pessoas para obter-se as respostas desejadas. Como instrumento de coleta de dados apresentou-se um questionário, que foi aplicado e validado, quanto à eficiência desse instrumento, Barros (1986) destaca as vantagens em sua aplicação porque o questionado tem anonimato, o que garante a sua liberdade para responder às questões, não tendo nenhuma influência do pesquisador, além do tempo ser maior para poder respondê-las de forma precisa.

\section{Os Sujeitos da Pesquisa}

Participaram dessa pesquisa seis professoras efetivas do $1^{\circ}$ ao $5^{\circ}$ ano de três escolas de Paracatu/MG, quatro docentes não quiseram participar da pesquisa, dessas seis, foram duas professoras de cada escola.

Essas escolas foram selecionadas porque foram contempladas com o Programa Residência Pedagógica, oferecido pela - Unimontes. As professoras serão tratadas como: E1P1 (escola um, professora um); E1P2 (escola um, professora dois); e assim por diante: E2P1; E2P2; E3P1 e E3P2. 


\section{Apresentação, análise e interpretação dos dados}

Quais as contribuições do processo formativo para o exercício da docência?

\begin{tabular}{|l|l|}
\hline Sujeitos & \multicolumn{1}{c|}{ Respostas } \\
\hline E1P1 & $\begin{array}{l}\text { Entendi que posso contribuir com a formação de indivíduos, instigando-os a } \\
\text { buscar soluções, pensar, criticar em um contexto ativo e modificador. }\end{array}$ \\
\hline E1P2 & Estudos, pesquisas e construção de saberes. \\
\hline E2P1 & $\begin{array}{l}\text { Ajudou a entender como realmente é ser regente de uma sala dos anos iniciais, } \\
\text { auxiliando com conhecimentos específicos necessários a prática. }\end{array}$ \\
\hline E2P2 & $\begin{array}{l}\text { Foi um aprendizado significativo, um norte para vivermos grandes experiências } \\
\text { no embate do trabalho em sala de aula. }\end{array}$ \\
\hline E3P1 & \begin{tabular}{l} 
É ele que te dá o suporte para direcionar as suas ideias, o caminho a ser seguido. \\
\hline E3P2
\end{tabular} $\begin{array}{l}\text { Todo o processo formativo é importante no exercício da profissão. Porém, a } \\
\text { prática deveria ser mais presente nesse processo formativo. }\end{array}$ \\
\hline
\end{tabular}

Fonte: a autora 2019

Pode-se perceber que o curso de formação para as professoras foi de aprendizagem significativa, capaz de oferecer teóricos saberes necessários para a prática docente, capacitando-as a impulsionar os educandos em sua criticidade. Nessa perspectiva, segundo Freire (1996), o bom professor é aquele que consegue, no momento da sua fala, levar o aluno a pensar, almejando construir conhecimento.

Quais foram os desafios em seu processo formativo?

\begin{tabular}{|c|l|}
\hline Sujeitos & \multicolumn{1}{|c|}{ Respostas } \\
\hline E1P1 & $\begin{array}{l}\text { Conciliar as atividades do cotidiano com as muitas horas de estudo em que me } \\
\text { propus, para que houvesse uma aprendizagem significativa. }\end{array}$ \\
\hline E1P2 & $\begin{array}{l}\text { Tempo, divergência de opiniões nos trabalhos em grupo e disponibilidade para } \\
\text { estágio. }\end{array}$ \\
\hline E2P1 & A desvalorização do curso. \\
\hline E2P2 & $\begin{array}{l}\text { O tempo, para conciliar trabalho, estudos, estágios e famílias, e também tive } \\
\text { dificuldades, pois fiquei muitos anos sem estudar. }\end{array}$ \\
\hline E3P1 & A falta de tempo disponível. \\
\hline E3P2 & Meu maior desafio foi conseguir conciliar a faculdade com o trabalho. \\
\hline
\end{tabular}

Fonte: a autora 2019.

A conciliação entre os estudos e o emprego, foram ressaltados pelas professoras como maior desafio. Nesse sentido, “[...] a escola flexível deve ser menos rígida, ter mais diálogo, facilitar a vida dos alunos para que possam conciliar trabalho e estudo" (SIQUEIRA, 2001, p. 239). Diante disso, percebe-se que para que concluíssem a graduação foi necessário 
que seus professores fossem abertos ao diálogo, considerando a condição das estudantes e também trabalhadoras, não dificultando sua inserção no mundo acadêmico, independentemente do trabalho ao qual estivessem vinculadas.

Quais os desafios em aplicar os saberes teóricos e práticos no exercício da docência?

\begin{tabular}{|c|l|}
\hline Sujeitos & \multicolumn{1}{|c|}{ Respostas } \\
\hline E1P1 & $\begin{array}{l}\text { Enfrentar a falta de estrutura pedagógica (falta de material didático, alunos com } \\
\text { problemas cognitivos e emocionais devido a desestrutura familiar e curto } \\
\text { espaço de tempo para planejar as aulas. }\end{array}$ \\
\hline E1P2 & $\begin{array}{l}\text { A Pedagogia é um curso muito amplo, então acho que o último período deveria } \\
\text { ser direcionado, assim diminuiriam os entraves na prática, exemplo: diário, } \\
\text { plano de aula e relatórios. }\end{array}$ \\
\hline E2P1 & $\begin{array}{l}\text { Encontrei poucas dificuldades e elas foram sendo sanadas a partir do momento } \\
\text { em que realmente compreendi o que era professor dos anos iniciais. }\end{array}$ \\
\hline E2P2 & $\begin{array}{l}\text { Falta de materiais didáticos, lidar com crianças com dificuldade psicológicas e } \\
\text { cognitivas e a maioria das vezes sem a ajuda da família. }\end{array}$ \\
\hline E3P1 & $\begin{array}{l}\text { Falta de material pedagógico, alunos desinteressados e pais sem compromisso } \\
\text { com a vida escolar dos filhos. }\end{array}$ \\
\hline E3P2 & \begin{tabular}{l} 
O maior desafio é conseguir aproximar o máximo possível teoria e prática. \\
\hline
\end{tabular} \\
\hline
\end{tabular}

Fonte: a autora 2019.

Os desafios explicitados pelas docentes são diversos como pode-se perceber: falta de materiais pedagógicos, falta de compromisso dos pais e alunos desinteressados. Do caráter diferenciado que devem ser as aulas, ressalta-se que os materiais didáticos são imprescindíveis para a qualidade de ensino-aprendizagem. Para Martinez (2002) os materiais servem para ordenar a vida da aula, podendo ser até um dispositivo privilegiado das políticas de controle.

Quais são as possibilidades do docente em aprimorar os seus saberes para melhor exercer a sua prática?

\begin{tabular}{|c|l|}
\hline Sujeitos & \multicolumn{1}{|c|}{ Respostas } \\
\hline E1P1 & Cursos de formação continuada. \\
\hline E1P2 & Sempre que tenho oportunidade, penso que deve ser contínuo. \\
\hline E2P1 & $\begin{array}{l}\text { Cursos extras, palestras com docentes renomados, e a troca de experiência com } \\
\text { colegas. }\end{array}$ \\
\hline E2P2 & $\begin{array}{l}\text { Participar de curso de capacitação, buscar conhecimentos sempre por meio de } \\
\text { pesquisas, cursos online, materiais pedagógicos que são oferecidos pelo sistema. }\end{array}$ \\
\hline E3P1 & Formação continuada. \\
\hline E3P2 & Através de cursos de qualificação e aprimoramento. \\
\hline
\end{tabular}


As docentes destacam a formação continuada essencial para aprimorar os saberes, considerando os professores como profissionais estratégicos para o desenvolvimento da sociedade. Conforme Nunes (2000), afirma que precisam de construção permanente do conhecimento e desenvolvimento profissional, produzindo-se a si mesmo, também se produz em interação com o coletivo. Também pode-se salientar a troca de experiência trocada que deve ser considerada como instrumento fundamental na aquisição de conhecimentos, momentos com compartilhamento de saberes podem ser feitos em reuniões escolares, pelo corpo docente.

Quais as possibilidades que o seu processo formativo lhe proporcionou para atuar na docência?

\begin{tabular}{|c|c|}
\hline Sujeitos & Respostas \\
\hline E1P1 & $\begin{array}{l}\text { Atuar como mediador de conhecimentos, que permita aos alunos desenvolver } \\
\text { suas habilidades. }\end{array}$ \\
\hline E1P2 & Conhecimento e a graduação exigida. \\
\hline E2P1 & $\begin{array}{l}\text { Possibilitou conhecimentos específicos sobre a infância e a adolescência, seus } \\
\text { processos de aprendizagem. }\end{array}$ \\
\hline E2P2 & $\begin{array}{l}\text { O curso veio nos proporcionar possibilidades de incluir novas metodologias e } \\
\text { conhecimentos, contribuindo assim para um ensino de qualidade. }\end{array}$ \\
\hline E3P1 & $\begin{array}{l}\text { Foi fundamental, pois através da minha formação que adquiri conhecimentos } \\
\text { suficientes para passar no concurso da área. }\end{array}$ \\
\hline E3P2 & $\begin{array}{l}\text { Uma prática reflexiva que visa sempre valorizar a realidade dos alunos, visando } \\
\text { assim a melhoria do ensino. }\end{array}$ \\
\hline
\end{tabular}

Fonte: a autora 2019.

A construção de conhecimentos e a mediação destes para os educandos ressalta a finalidade da Educação, que é cumprida no processo formativo dos professores para atuarem na docência, uma vez que a Educação representa tudo aquilo que: "pode ser feito para desenvolver o ser humano e, no sentido estrito, representa a instrução e o desenvolvimento de competências e habilidades" (VIANNA, 2006, p. 30). Percebe-se que o curso de formação permite contribuir para um ensino de qualidade, por formar professores para mediar novos conhecimentos. 
As teorias abordadas no Curso de Pedagogia contribuíram para a efetivação da sua prática docente?

\begin{tabular}{|c|c|}
\hline Sujeitos & Respostas \\
\hline E1P1 & Sim. Já que o curso é todo voltado para essa finalidade. \\
\hline E1P2 & Pouco. \\
\hline E2P1 & $\begin{array}{l}\text { Sim, pois muitas delas auxiliam no processo de formação de um bom docente. } \\
\text { Ajudando-o a dominar o conteúdo e a didática. }\end{array}$ \\
\hline E2P2 & Sim, visto que todas eram voltadas para a prática docente. \\
\hline E3P1 & Com certeza. \\
\hline E3P2 & $\begin{array}{l}\text { Sim, porém na maioria das vezes a teoria está longe da realidade encontrada em } \\
\text { sala de aula. }\end{array}$ \\
\hline
\end{tabular}

Fonte: a autora 2019.

Sendo o curso de Pedagogia composto de teoria e prática, as teorias abordadas são imprescindíveis para a atuação do professor em seu campo de atuação. As professoras destacam que as teorias aprendidas durante o processo de formação foram muito importantes, salientando que é importante se atentar a realidade do aluno para conseguir êxito no processo ensinoaprendizagem. Diante disso Aquino (1999, p. 43), enfatiza que a escola: "deve se tornar mais interessante para os alunos e alunas que a frequentam e os conteúdos precisam estar mais contextualizados em seu cotidiano e nas suas necessidades".

Durante a sua formação acadêmica no Curso de Pedagogia, os professores utilizaram teoria e prática? Explique:

\begin{tabular}{|c|c|}
\hline Sujeitos & Respostas \\
\hline E1P1 & $\begin{array}{l}\text { Sim. Com algumas horas extra acadêmica, com oficinas, palestras e o próprio estágio } \\
\text { supervisionado. }\end{array}$ \\
\hline E1P2 & Às vezes. \\
\hline E2P1 & $\begin{array}{l}\text { Sim, ouvíamos a teoria e a colocávamos em prática na sala e nos estágios e na sala de } \\
\text { aula. }\end{array}$ \\
\hline E2P2 & $\begin{array}{l}\text { Sim, além da teoria que estudávamos em sala de aula, desenvolvíamos oficinas dentro } \\
\text { e fora do espaço escolar, participávamos de oficinas, palestras e outras atividades } \\
\text { extracurriculares. }\end{array}$ \\
\hline E3P1 & Sim, as práticas foram oficinas e estágios. \\
\hline E3P2 & Pouco, o que mais era visto era a teoria. \\
\hline
\end{tabular}

Fonte: a autora 2019. 
A teoria e prática são partes indispensáveis no processo de formação dos professores, as docentes destacam que a teoria e prática foram utilizadas pelos profissionais que trabalharam em seus cursos de formação, a teoria por meio de estudos bibliográficos e a prática por meio de oficinas, palestras, bem como estágio supervisionado.

Dessa forma, Kuenzer (2003), ao refletir sobre a práxis, afirma que este é um processo resultante do movimento constante entre teoria e prática, entre pensamento e ação, produzindo conhecimento, e por isto é capaz de revolucionar o que está dado, transformando assim a realidade. A partir dos estudos teóricos os acadêmicos do Curso de Pedagogia podem compreender as metodologias, a didática para o exercício da prática docente.

Qual a importância dos saberes teóricos e práticos no curso de formação de professores?

\begin{tabular}{|c|c|}
\hline Sujeitos & Respostas \\
\hline E1P1 & $\begin{array}{l}\text { Saber que um professor se molda, conforme aplica a prática e reflete sobre a } \\
\text { teoria e transforma-a na busca de novas práticas que facilite a aprendizagem dos } \\
\text { alunos. }\end{array}$ \\
\hline E1P2 & Aprendizagem, apesar da prática ser diferente, temos uma base com o curso. \\
\hline E2P1 & A teoria te mostra como é e a prática te mostra como realmente é. \\
\hline E2P2 & $\begin{array}{l}\text { Essencial para nossa formação acadêmica e para enriquecer nossa vida como } \\
\text { profissional, preparando-nos para os desafios que iremos encontrar no decorrer } \\
\text { das nossas vidas. }\end{array}$ \\
\hline E3P1 & $\begin{array}{l}\text { São fundamentais, pois eles dão embasamento na preparação para adentrar em } \\
\text { uma sala de aula. }\end{array}$ \\
\hline E3P2 & São a base e o norteio para o exercício da docência. \\
\hline
\end{tabular}

Fonte: a autora 2019.

Os saberes teóricos e práticos no curso de formação de professores são salientados como essenciais para a construção de conhecimentos e atuação profissional. Lima (2002), afirma que ao ter acesso as teorias, as situações práticas podem ser desenvolvidas de forma reflexiva, já que estão sendo fundamentadas.

\section{Considerações Finais}

Pode-se compreender que são muitos os desafios e as possibilidades sobre a formação inicial de professores, mas que os saberes compartilhados e adquiridos no curso de de Pedagogia é suma importância, buscando compreender as questões da prática docente, aliado a teoria que possibilitam um processo de ensino-aprendizagem significativo. 
Nesse sentido, os questionários explicitados nas tabelas foram possíveis perceber que a estratégia mais utilizada pelos professores, foi à aproximação do aluno, visando construir estratégias de ensino de acordo com a realidade deste. Justificou-se que as possibilidades e os desafios encontrados enquanto acadêmico do Curso de Pedagogia, pode refletir e analisar sobre a formação obtida no curso, tendo em vista o exercício da docência.

Compreendeu-se que os professores ao pensarem sobre o seu curso de formação, ressaltam a importância da teoria e da prática para que a execução do seu trabalho seja proveitosa. Notou-se que reconhecem a necessidade de formação continuada por parte docente para que se capacitem constantemente, bem como a troca de experiência que também é privilegiada para enriquecer conhecimentos e buscar soluções didáticas para eventuais problemas em sala de aula.

Em virtude dos aspectos abordados nesta pesquisa, espera-se que esta contribua para futuras investigações no campo educacional, possibilitando uma reflexão e uma análise da formação de professores, bem como os novos desafios e possibilidades que possam surgir mediante os saberes teóricos e práticos no processo formativo do acadêmico de pedagogia.

\section{Referências}

ANDRÉ, M. O papel da pesquisa na formação e na prática dos professores. Campinas, SP: Papirus, 2001.

ARANHA, Maria Lúcia de Arruda. História da educação e da pedagogia: geral e Brasil. 3 ed. rev e ampl. SP: Moderna, 2006.

AQUINO, J. G. Autoridade e Autoritarismo na Escola: alternativas teóricas e práticas.

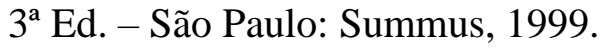

BARROS, Aidil Jesus Paes de; LEHFELD, Neide Aparecida de Souza. A metodologia e a universidade. In: BARROS, Aidil Jesus Paes de; LEHFELD, Neide Aparecida de Souza. Fundamentos de metodologia: um guia para a iniciação científica. São Paulo: Mc GrawHill, 1986. p. 1-14.

BOLZAN, Dóris Pires Vargas. Formação de professores: compartilhando e reconstruindo conhecimentos. - Porto Alegre: Mediação, 2002.

BRASIL. Conselho Nacional de Educação. Define as Diretrizes Curriculares Nacionais para a formação inicial em nível superior (cursos de licenciatura, cursos de formação pedagógica para graduados e cursos de segunda licenciatura) e para a formação continuada. Resolução CNE/CP n. 02/2015, de $1^{0}$ de julho de 2015. Brasília, Diário Oficial [da] República Federativa do Brasil, seção 1, n. 124, p. 8-12, 02 de julho de 2015. 
maio de 2001. Diretrizes Curriculares Nacionais para a Formação de Professores da Educação Básica, em nível superior, curso de licenciatura, de graduação plena. Portal MEC. Brasília, DF: MEC/CNE/CP, 2001. Disponível em: http://portal.mec.gov.br/cne/arquivos/pdf/009.pdf acesso em: 06 abril. 2019.

BRASIL. Lei de Diretrizes e Bases da Educação Nacional. Lei número 9394, 20 de dezembro de 1996.

Ministério da Educação. Secretaria de Educação Fundamental. Referenciais para a Formação de professores. Brasília: 2002.

Resolução CNE/CP 1/2006. Diário Oficial da União, Brasília, 16 de maio de 2006.

Resolução CNE/CP 1, de 18 de fevereiro de 2002. 2002 a. Institui Diretrizes Curriculares Nacionais para a formação de professores da Educação Básica, em nível superior, curso de licenciatura, de graduação plena. Disponível em http://portalmec.gov.br. Acesso em 06 de abril de 2019.

Resolução CNE/CP no 2, de 19 de fevereiro de 2002. 2002 b. Institui a duração e a carga horária dos cursos de licenciatura, de graduação plena, de formação de professores da Educação Básica em nível superior. Disponível em http://portalmec.gov.br. Acesso em 09 de abril de 2019.

CANDAU, V.M.F. Formação Continuada de professores: tendências atuais.in REALI, AM. de M.R. e MIZUKAMI, M.G.(org). Formação de professores: tendências atuais. São Carlos: EDUSFSCar,1996.

Universidade e formação de professores: Que rumos tomar? In: CANDAU, Vera Maria. (org.) Magistério, construção cotidiana. Petrópolis: Vozes, 1997

DAMAZIO, M.S.; PAIVA, M. F. O ensino da educação física e espaço físico em questão. 2005. v.1, p. 193

DEMO, P. (1999). Questões para a teleducação. $2^{a}$ ed. Petrópolis: Vozes.

FRANCO, Maria Amélia do Rosário Santoro. Pedagogia como ciência da educação. 2 ed. rev e ampl. SP: Cortez, 2008.

FREIRE, P. Pedagogia da autonomia: saberes necessários à prática educativa. São Paulo: Paz e Terra, 1996.

GALIAZZI, Maria do Carmo. Educar pela Pesquisa: ambiente de formação de professores de Ciências. Ijuí: Ed. Unijuí, 2003.

GATTI, B.; NUNES, M. M. R. (Orgs.). Formação de professores para o ensino fundamental: estudo de currículos das licenciaturas em Pedagogia, Língua Portuguesa, Matemática e Ciências Biológicas. São Paulo: FCC; DPE, 2009.

GOLDENBERG, M. A arte de pesquisar. Rio de Janeiro: Record, 1997. 
HARGREAVES, A. Aprendendo a mudar: o ensino para além dos conteúdos e da padronização. Porto Alegre: Artmed, 2002.

IMBERnÓN, F. (2001): Formação Docente e Profissional: Formar-se para a mudança e a incerteza, S. Paulo, Cortez.

PARREIRA. Lelis. Pedagogia, como ciência da educação. Cadernos de Pesquisa. Vol. 37, n. 131, São Paulo, mar/Aug. 2007.

LIMA, Emilia Freitas de. O Curso de Pedagogia e a nova LDB: vicissitudes e perspectivas. In: MIZUKAMI; Maria das Graças N.; REALI, Aline Maria De Medeiros R. Formação de professores: práticas pedagógicas e escola. São Carlos: EDUFSCAR, 2002. p. 205-216.

LEFEHLD, N.A.S.; BARROS, A.J.P. Projeto de pesquisa: propostas metodológicas. Petrópolis/RJ: Vozes, 1991

LÜDKE, M. Avaliação institucional: formação de docentes para o ensino fundamental e médio (as Licenciaturas). Estudos e Debates, n. 19, p. 137-196, 1997.

O Professor, seu saber e sua pesquisa. In:. Educação e Sociedade, ano XXII, n . 74. Campinas: Cedes, 2001 b.

KUENZER, Acácia Z. Competência como Práxis: Os Dilemas da Relação entre Teoria e Prática na Educação dos Trabalhadores. Boletim Técnico do SENAC, Rio de Janeiro, Vol. 29, nº1. jan/abr., 2003.

MARCELO, C. Formação de professores para uma mudança educativa. Porto: Porto Editora, 1999.

MARTINEZ B, J., (2002). Políticas del libro de texto escolar. Madrid: Morata. RIO DE JANEIRO, 2011.

MARQUES, Mario Osorio. A formação do profissional da educação. Ijuí: Ed. UNIJUÍ, 2000. 240p. (Coleção Educação; 13)

MAZZOTTI, Tarso. Estatuto de cientificidade da Pedagogia IN: PIMENTA, Selma Garrido (Org.). Pedagogia, ciência da educação?. São Paulo: Cortez. 1996.

MIZUKAMI, Maria da Graça Nicoletti. Aprendizagem da docência: algumas contribuições de L. S. Shulman. Revista Centro de Educação. Edição 2004, v.29, n.2. Disponível em http://coralx.ufsm.br/revce/revce/2004/02/a3.htm. Acesso em 06 abr. 2019.

NEGRINE, Airton. Terapias Corporais: a formação pessoal do adulto. Porto Alegre: Edita, 1998.

NÓVOA, Antônio. Concepções e práticas de formação continuada de professores. In: TAVARES, José (Org.). Formação contínua de professores: realidades e perspectivas. Alveiro: Universidade Alveiro, 1991.

(coord.). Formação de Professores e Profissão Docente. In: Os professores e a sua formacão. Lisboa: Publicações Dom Quixote/IIE, 1992. 
(coord.). Os professores e a sua formação. Publicação Dom Quixote. Lisboa,

Portugal: Instituto de Inovação Educacional, 1997.

Cúmplices ou reféns? Nova Escola. São Paulo: Abril; n. 162, p. 14-15, mai. 2003.

NUNES, Cely do S. C. Os sentidos da formação contínua. O mundo do trabalho e a formação de professores no Brasil. Campinas, SP: Unicamp, 2000. (Tese de doutorado)

OLIVEIRA, Dalila Andrade. A nova regulação de forças no interior da escola: carreira, formação e avaliação docente. Revista Brasileira de Política e Administração da Educação, ANPAE, v. 27, n. 1, p. 25-38, jan./abr., 2011.

PIMENTEL, Edna Furukawa. A epistemologia e a formação docente: reflexões preliminares. In: RAMALHO, Betânia Leite; NUNES, Claudio Pinto; CRUSOÉ, Nilma Margarida de Castro (org.). Formação para a docência profissional: saber e práticas pedagógicas. Brasília: Liber Livro, 2014. p. 15-38

PISTRAK. Moises Melonovich. Fundamentos da Escola do Trabalho. São Paulo: Brasiliense, 1981.

Artigo recebido em: 12/08/2020. Artigo aceito em: 20/08/2020. 